\title{
More than one road goes to Rome: Understanding the complex behavioral solutions of mobile money clientele from the lens of fsQCA
}

\author{
Enock Mintah Ampaw ${ }^{1 *}$, Albert Adu-Sackey ${ }^{1}$, Samuel Baffoe ${ }^{1}$, Joseph Frempong ${ }^{2}$, Nborlen Mark \\ Nte-Adik ${ }^{3}$ and Jacob Azaare ${ }^{4}$ \\ 1 Applied Mathematics Department, Faculty of Applied Science and Technology, Koforidua Technical University, Post Office \\ Box KF980, Koforidua E/R, Ghana, West Africa \\ 2Marketing Department, Faculty of Management and Business Studies, Koforidua Technical University, Post Office Box \\ KF981, Koforidua E/R, Ghana, West Africa. \\ 3 Assemblies of God Hospital, Post Office Box 29, Saboba \\ N/R, Ghana, West Africa \\ ${ }^{4}$ School of Management and Economics, University of Electronic Science and Technology of China, No. 2006 Xiyuan Ave, \\ West-High-Tech Zone, Chengdu, China. \\ ${ }^{1 *}$ Correspondence: sendtoampam@yahoo.com
}

\begin{abstract}
The study was commissioned to investigate the complex behavioral dispositions of the mobile money service industry in Ghana, and its associated operational challenges. To achieve this, the views of 417, participants were sampled via a structured survey instrument. Tosmana and AMOS Graphics were used to analyze the sample data. The findings of the study demonstrate that the behavioral dispositions of mobile money clientele can be explained through twelve complex solutions. The six-factor model of the study constructs produced an overall solution coverage of 0.94 , and an overall solution consistency of 0.80 . Furthermore, the AVE and Cronbach's alpha statistics of the study constructs were found to be above the recommended threshold of $>0.5$ and $\geq 0.7$, respectively. Moreover, cyber fraud, risky service landscape, poor network, insufficient electronic funds, unforgiven competition, and low financial literacy were identified as the main challenges bedeviling the mobile money industry. It is therefore, recommended that mobile money service providers as a matter of urgency must devise strategies to arrest these challenges in order to heighten service quality in the industry. Again, to ensure market leadership within the mobile money service industry, managers must develop varied product offerings to meet customers' expectation in each stratum of the twelve complex solutions as enshrined in the findings of the study.
\end{abstract}

Keywords: Mobile money, perceived quality, fsQCA, MNO, behavioral intentions, financial inclusion, complexity theory.

Citation: Ampaw, M. E., Adu-Sackey, A., Baffoe, S., Frempong, J., Nbolen, M. N. A. and Azaare, J. (2021). More than one road goes to Rome: Understanding the complex behavioral solutions of mobile money clientele from the lens of fs QCA. International Journal of Technology and Management Research (IJTMR), Vol. 6 (2): Pp.1 -20 .

Received: January 3, 2021

Accepted: September 1, 2021 


\subsection{Introduction}

The ecosystem of the global financial service landscape has been shaped vastly in recent years through unparalleled access to mobile phone devices worldwide. Both anecdotal details and existential evidence collaboratively espouse that the remarkable penetration of mobile phone devices, especially, in sub-Saharan Africa (SSA) has markedly dwarfed the century years problem of disproportional accessibility to financial service (GSMA, 2017). Prior literature on financial technology (Fintech) emphasizes that the financial service landscape of the African continent is bedeviled by sluggish and unimpressive penetration of traditional financial services. Examples of most widely publicized problems which have occasioned the poor accessibility to mainstream financial service in Africa are minimum balance requirement, acute financial illiteracy, uneven distribution of banking facilities and its resultant cost of travelling (Shem, Teresa, \& Maureen, 2017). Specifically, only 20\%, of the active workforce in the SSA have been identified to have access to financial services. It is also estimated that $66 \%$, of the population in the subregion do not have access to traditional banking services accounts. This disturbing revelation is empirically, illustrated in Figure 1. Other empirical sources link the problem of poor accessibility to formal banking services in Africa to underdeveloped financial service landscape (Ghana Banking Survey, 2014; Demirguc-Kunt, Klapper, Singer, Ansar, \& Hess, 2018) .

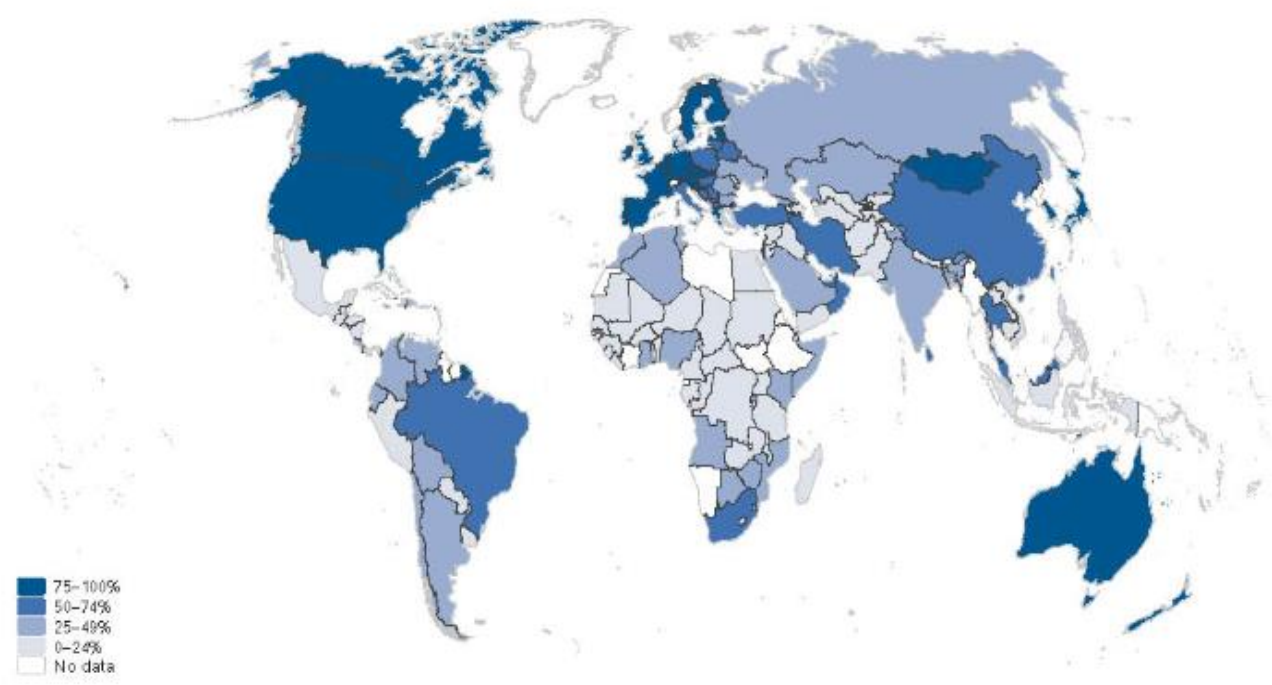

Figure 1. Global distribution of the adult population with mainstream banking account (GMSA, 2017)

Empirical reports on the financial service landscape of Africa are now told contrarily since the last decade owing to the unprecedented penetration of mobile phone devices and the unwavering attempt by Mobile Network Operators (MNOs) to attract extra revenues from nontraditional sources. The first ever mobile banking service to be launched on African soil, M-PESA is credited for its butterfly effect within the spheres of financial intermediary (Gahigi \& Moses, 2017). Subsequently, the huge underserved and unbanked populations of yesteryears in Africa have been dwarfed impressively in recent times. In other words, the birth of the MMS in Africa has provided a niche market to address the century years challenges of accessing financial intermediaries by the lion's share of the population. Facilities for MMS are presently littered across the length and breadth of most streets in Africa to provide exclusive 
and customer-friendly banking services to the consuming public. Through lean service production, the MMS has markedly deepened the course of financial inclusion via the provision of economical and convenient banking services to those at the bottom of the pyramid (M. Ghana, 2018).

MMS has evolved as a disruptive business model in the fabric of the African financial service industry. According to the GSMA, MMSs are presently running in ninety countries worldwide. Quantitatively, out of a total of 277 MMSs across the globe, 140 of them can be found in Africa. This affirms the pervasive nature of the service on the continent (GSMA, 2017). Undoubtedly, the MMS subsector of Fintech has received a limited attention in prior literature. Most of the studies on the MMS subsector fall under the umbrella of anecdotal details. Furthermore, the background of most of the studies on Fintech are either on developed or emerging economies. The foregoing has created a chasm and imbalance in literature and thus, need to be addressed. A handful of research has been carried out in Africa on MMS (Ardey, 2016; Demirguc-Kunt et al., 2018; Shem et al., 2017), however, not with a clear-cut application of asymmetric methodology to wholly unravel the complex behavioral solutions of the MMS clientele, and the associated demand/supply-side challenges of MMS stakeholders. These prior studies are overwhelmed and inundated with symmetric methodologies and thus, have woefully failed to appreciate the complex nature of the MMS consumers behavior. The illustrated identified gaps are however, intended to be addressed in this study.

\subsection{The overview of the banking landscape and the payment system of Ghana}

The financial technological waves in line with the global financial infrastructural development have impacted positively on the banking ecosystem of Ghana. Traditional banking practices are succumbing to financial technologies through the promulgation of new laws and regulations to govern economic transactions as far as international best practices are concern. Specifically, the Bank of Ghana has demonstrated an overwhelming support for the implementation of vigorous digital-led cash-lite financial service system most commonly referred to as digital financial service (DFS for short) to enhance the uninterrupted flow of goods and services among economic agents. The DFS initiative is tailored to include activities such as bill payments, digital savings, government payments, and credit extension. The motivation for this action is to equip financial institutions with the necessary resource to reach scale by honoring both domestic and international obligations (Max \& McKay, 2018).

In the light of this, the Bank of Ghana has recently embarked on a policy adjustment program which saw the holistic review of the nation's laws on Payment Systems in furtherance of financial service innovation and application of financial technology (i.e. Act 662) (G. C. Bank, 2017b). In view of this, the new policy on payment system of Ghana is expected to deepen financial inclusion and financial literacy while serving the overall purpose of financial service digitization and innovation. The new payment system - Payment Systems and Services Act, 2019 (Act 987) is expected to boost trading activities through the application of electronic money. Within the ambit of the law, the Bank of Ghana remains the sole regulator of the banking industry in Ghana, and by exercising this special statutory mandate, the Bank of Ghana has recently scaled down the number of banking institutions to twenty-three to enhance efficiency in the industry (G. C. Bank, 2017a). Again, as part of the Bank of Ghana's routine regulatory policy to ensure capacity building in the industry, the minimum capital requirement for operating a banking institution has been increased to 400 million Ghana cedis ( $\$ 85$ million) since 2018 (Awadzi, 2018). 


\subsection{The mobile banking ecosystem in Ghana}

The mobile phone penetration rate in Ghana is among the few highest in the world. The adoption of internet-related services is also phenomenal. To this end, financial literacy and inclusion have been deepened through the joint effort of the telecommunication and the banking industries. Specifically, the population of Ghana's mobile data subscription soared to 22,865,821, as of September, 2017. This represents mobile phone penetration rate of $79.94 \%$ (Owusu, Atiemo, \& Appiah, 2019).

According to Owusu et al., (2019), the mobile voice subscription number of Ghana stood at 35,984,280, as of April, 2017, while the Internet's users' population was recorded as 7,958,675, in the same period. This means that $27.8 \%$ of the Ghanaian population use Internet in their socio-economic endeavors. This intriguing development in the Ghanaian telecommunication space has triggered diversity in the provision of retail banking service (B. of Ghana, 2017). This has enabled most banks in Ghana to reach scale through constant provision of quality service to the banking public.

\subsection{Behavioral intention towards continuous usage}

According to information systems (IS) theories, brand loyalty is mostly discussed as an inertia concept. Against this schema, Polites \& Karahanna (2012) argued that inertia "is user attachment to, and persistence in using an incumbent system even if there are better alternatives or incentive to change". Most prior research, thus, express inertial as the attitudinal disposition of consumers to maintain their consumption status quo unconditionally (R. Lee \& Neale, 2012). By implication, inertia, eschews switching behaviors among consumers. Again, the constructive influence of consumers' inertia tendencies translates into excellent market performances of the associated inertia of goods and services. It is also evinced that within the ecosystem of information technology and information systems, the inertia construct is extremely influential and powerful than other competing antecedents of consumers' behavioral intention such as cost. In line with this assertion, Anderson \& waminathan, (2011) empirically, forwarded that oftentimes, the inertia disposition of consumers toward brands enjoin them to purchase the same brands on the grounds of reasoned action or habit - i.e. situational cues as opposed to critical assessment of perceived economic cost or benefit.

Anderson \& Swaminathan (2011) promoted that whenever mobile service subscribers become attached or familiar with the content of their service providers, as enshrined in their value proposition they turn to become super loyal due to several factors. These factors include the tendency to eschew the uncomfortable condition of having to learn the soft skills needed for the operation of new products whenever switching is done; and the cost of searching, which is necessitated by switching decisions. Prior studies indicate that switching cost acts as one of the critical inhibiting factors of consumers' disloyalty towards brands. Furthermore, Lee \& Neale (2012) found that the impact of the switching cost on consumers' post-purchasing behaviors will be less effective given that consumers constantly display a considerable degree of inertia towards a brand. According to Wei-Tsong et al (2019), perceived service quality (security, ease of use, trust, satisfaction, among others) in mobile-related service inform consumers decision on the time and effort required to master the applications of alternative offerings. Consequently, the margin of consumers' inertia will be significantly higher towards their current brands. 


\subsection{The nexus between security and MMS adoption}

The F. R. Bank (2017) posits that the adoption and continuance usage of mobile financial service are immensely obstructed by genuine security and privacy concerns as a result of plausible remote hacking activities. In effect, researchers have established a correlation between subscribers' behavioral disposition toward mobile banking and the perceived technological security of service providers (ChauShen, 2013). To this end, the perception of risk by subscribers is critically analyzed before settling for a given digital financial service. For instance, ChauShen (2013) identified that perceived risk notion about electronic services are on the rise in communities with relatively high level of risk aversion dispositions. As a result, electronic commerce is affected negatively. Perceived risk has been defined as "a perception about implicit risk in using the open Internet infrastructure to exchange private information, and it is often operationalized as a multi-dimensional construct" (ChauShen, 2013). Electronic banking literature has recognized that the key areas of risk concerns relative to adoption and continuous utilization of electronic banking are finance, performance risk, privacy, and security. Zhao et al (2008), however, argued that perceived risk in innovative services can be decomposed into five namely, time, security and privacy risk, financial risk, psychological risk, and performance risk.

Time risk factors relative to MMS constitute the dedication of additional or extra time in gaining sufficient knowledge and skill on how to use MMS products efficiently in order to optimize their gains. In generic sense, the time risk factor relates to the time span requirement that one needs to be familiar with an innovative technology in order to make the initial adoption effort or decision (Littler \& Melanthiou, 2006). On the other hand, security or privacy risks connote the most serious drawback of MMS and most electronic services as a result of vulnerabilities, hacking and unwarranted third-party intrusions by authors of malwares and other cyber criminals. The operations of these miscreants cause loss of money and access to confidential information of subscribers in financial technology services (Littler \& Melanthiou, 2006). Consequently, most potential MMS subscribers have cultivated an aversion and a lackadaisical attitude towards the adoption of MMS. Moreover, post-adoption subscribers who have ever been victims of cyber-attacks oftentimes refrain from continuance usage of MMS.

Financial digital risk relates to plausible loss of money by subscribers which can either be attributed to system deficiency or hacking activities which in effect results in misappropriation of money. For instance, there are plethora of reported incidents where electronic funds have been wired unintentionally to wrong recipients account due to system lapses and cybercrime activities (Littler \& Melanthiou, 2006). On the other hand, psychological risk in MMS entails individual's perceptual dispositions which have the wherewithal to negatively affect the adoption of innovative services.

Lastly, performance risk embodies a gamut of factors which are perceived to be unfavorable to the smooth performance of MMS. These include the inability of MMS subscribers to go through a successful transaction process at their convenient time. The efficacy of the MMS business model in addressing the financial service needs of the public is also of prime concern (Littler \& Melanthiou, 2006). 


\subsection{The nexus between perceived quality and MMS adoption}

Empirically, the perception of service quality is diffused through social networking platforms on the bases of members experience with affiliated brands. Word-of-mouth referral is considered as one of the key conduits by which service quality recommendations are made. Perceived quality is scholarly believed to be very instrumental in the creation of brand equity. One of the cardinal factors which underpin both pre-behavioral and post-behavioral dispositions of mobile financial services clientele is perceived service quality. This is due to the relative level of risk factors in the E-commerce industry. Service quality (SERQUAL) encompasses a condition where a delivered service is able to meet the expectation of clients. By extension, we defined SERQUAL within the MMS industry as the overall disposition about the relative superiority or otherwise of service providers. Other empirical sources project service quality as the difference between consumers' expectations and their perceptual disposition relative to product offerings.

There is a lot of studies which recognize perceived service quality as the anchor of mobile banking customers loyalty. Perceived service quality engenders customers' satisfaction. It also serves as the foundation for word-of-mouth referrals. The MMS subscriber base translates industry players' ability to advance secure, convenient, affordable and timely offerings as quality of service, and on the bases of these, the former pledge their allegiance to the latter (Zeithaml, Berry, \& Parasuraman, 1985).

\subsection{The nexus between satisfaction and MMS adoption}

The satisfaction of customers resonates with their continuous product utilization - i.e. their post-purchase behavioural dispositions. Generally speaking, customers visibly express their satisfactory behaviours when they request more of a product or service previously accessed. The contrary is also true. Prior studies opine that satisfaction is the total appraisal on a product offering against the framework of consumers accumulated consumption experience.

Customer satisfaction has been categorised into two - cumulative satisfaction and transaction-specific (Boulding, Kalra, Staelin, \& Zeithaml, 1993) . From the angle of cumulative satisfaction, customer satisfaction is actualised as a result of general assessment or evaluation conducted on a product offering with practical consumption experiences. To this end, (Oliva, Oliver, \& MacMillan, 1992) espoused that cumulative satisfaction is a derivation of chronological purchases which translate into a compelling trust that a service provider has practically fulfilled an expected and assured value proposition. Post-purchase behavioural dispositions of customers are therefore, anchored on their cumulative satisfaction or experience. On the other hand, transaction-specific satisfaction has been expressed as the type of consumer satisfaction which is linked to a precise satisfaction borne out of a particular transaction. With inspiration from cumulative satisfaction, Wei-Tsong et al., (2019), defined mobile-mediated financial services customer satisfaction as "an emotional response based on users' overall evaluation of expectations and experiences derived from previous interactions with $\mathrm{m}$-service". It can be extrapolated from the foregoing narrative that MMS subscribers will continually partner with service providers whose products match their satisfaction margins. 


\subsection{The nexus between brand trust and MMS adoption}

The concept of trust has gained an immeasurable popularity in customer relationship literature due to its intrinsic role in customer loyalty. It has been defined in several ways by academics and professionals to reflect positive connotations or gestures which are advanced by customers towards brand owners. For instance, Boateng (2016), defined trust as the guarantee from a customer to display positive attitude towards a brand unconditionally. Research posits that trust naturally dispel the element of uncertainty in human interactions. Thus, trust fosters cordial social bonds necessary for efficient business transactions among economic actors who are aiming at the attainment of their socio-economic ends. According to Lee \& Jee (2016), brand trust is the belief that a brand is capable of proving the value proposition of service providers. In the context of mobile phones and its related services, Hawass (2013), defined brand trust as "a relational chemistry upon which the customer is emotionally and rationally attached to a specific brand name".

Bank (2017) accentuates that with the upsurge in cybercrimes, and rampant hacking of classified and private data of digital service customers, trust and security have emerged as core determinants of financial services adoption. In line with this, Donovan (2012), contextualised that the constant assurance by MMS providers that subscribers' funds are secure, safe and can be withdrawn whenever the need arises will be an effective mechanism to boost the rate of adoption and constructive post-adoption behaviours of MMS subscribers. In similar fashion, Pavlou, et al., (2003), contend that clients who nurse the idea of impressive structural assurance trust towards service providers without an iota of doubt will equally believe that their personal data and funds are given full protection against cybercrimes.

\subsection{The nexus between brand equity and MMS adoption}

Kotler \& Pfoertsch, (2007), defined brand as "the name associated with one or more items in the product lines which is used to identify the sources of character of the item (s)". Similarly, Hoeffler \& Keller (2003), contend that the inventions of new logos, names, symbols, among others are equally classified as independent brands. In essence, the function of a brand is basically to engender product differentiation. Aaker (1991), considered brand to be an essential asset of firms, and thus, function as their trademarks. On the other hand, Kohli \& Thakor (1997), advanced that the quest for achieving a powerful and distinctive brand image has become the holy grail among industry players.

Business analytics literature has identified eight core functions of a brand which serve as a constant motivation to brand inventors. These are: identification, ethical, characterization, hedonic, guarantee, continuity, ethical and optimization (Kapferer, 1998). In detail, identification embodies the quality of a product which makes it to be seamlessly noticed among competing ones. The ethical functionality of a brand involves service producers' assurance of abiding by their value proposition in order to materialize the expectation of consumers (Kapferer, 1998). Characterization as expressed by Kapferer (1998), encapsulates the ability of brand owners to constantly maintain the quality of their brand as positioned on the mind of the public. It is evident in extant literature that characterization correlates positively with customer loyalty and its antecedents including satisfaction, perceived quality, trust and security (Gwahula, 2016).

In the context of brand functionality, the practicality of a brand is linked to time and energy saving possibilities experienced by consumers whenever repurchase decisions are made. The cost of searching has empirically been 
identified as a major factor which impedes new product adoption and continuance usage. Consumers are therefore, loyal to brands whose producers assure them constant supply regardless of geospatial constraints and vice versa. Similarly, Kapferer, 1998, asserts that the continuity of a brand is observed through accumulated years of usage, experience, familiarity, and accrued satisfaction to users.

A brand may perform a hedonic functionality if it is attracted to people on the bases of its physical features such as size, weight, logo, shape, color, among others. Oftentimes, consumers are very much particular about the consistency of brand quality regardless of where or from whom it is bought. Thus, brand owners always endeavor to keep a brand which goes beyond physical product differentiation by guaranteeing consistent brand quality as well. Kapferer (1998) argued that brand optimization connotes the concept of purchasing the best brand in the multitude of brands. Essentially, brand optimization heightens consumers' utility and the satisfaction derived from competing products. Extension can therefore, be made that the behavioral dispositions of MMS subscribers are shaped by the brand of service providers.

\subsection{Complexity theory and $f_{s} Q C A$}

Complexity theory goes beyond the limitations of traditional statistics - i.e. symmetric methodologies. Complexity theory is defined as a scientific discipline which explains the independent emergence of coherent systems from the lens of Chaos Theory. Symmetric methodologies such as structural equation modelling (SEM) and multiple regression are pigeon-holed by assumptions of linearity, addictive effects, and causal symmetry among the dependent and the independent factors. These invariably make them predictable (Ragin \& Fiss, 2008). Moreover, the approximation of the net effects of independent variables on the bases of dependent variables is the norm and routine in traditional statistics (Wu, Yeh, Huan, \& Woodside, 2014).

The conditions within which traditional statistics are executed reduce them to Unifinality outcomes (Woodside, Prentice, \& Larsen, 2015). Unifinality is premised on the proposition that there is always a single optimal solution as the best fit for behavioural outcomes. This claim is however, sharply contested within the framework of complexity theory. Symmetric methodologies do not have the oomph for analysing configural recipes which are likewise effective in achieving the same outcome (Equifinality). Stated differently, the theoretical provisions of traditional statistics disqualify it for counterfactual analyses.

Quite a significant number of studies under the purview of social science use symmetric methodologies. These studies are therefore, bound to the dictates of simple theories. "... researchers in the behavioural and management sciences using symmetric tests (e.g. correlations and regression coefficients) stop their analysis after finding statistical support significant for directional relationships" (Woodside, Garbor, \& Megehee, 2017). Reports of such nature are inconclusive and thus, create an avenue for criticism (Wu et al., 2014). Complexity theory addresses the theoretical deficiencies of symmetric methodologies by proposing asymmetric methodologies such as fuzzy set qualitative comparative analysis (fsQCA). Contrary to symmetric methodologies, asymmetric concepts are characterized by the principal of Equifinality. Specifically, Equifinality provides support for non-linearity between the dependent and independent variables. In effect, complexity theory advocates that there are always uncertainties surrounding predictive systems. Complexity theory dictates that the presence of a very high symmetric association between the 
dependent and independent variables is virtually not in existence. It therefore, makes a case for counterfactual analysis contrary to model fit diagnostics and net effect schemes of symmetric methodologies (Ragin \& Sean, 2009). FsQCA is a case-oriented methodology for embarking on counterfactual analysis. It applies set theoretic concepts and fuzzy logic to address the limitations of symmetric methods namely, net effect, large Ns and, Unifinality. “... QCA starts by assuming that causation is complex, rather than simple" (Ragin \& Sean, 2009). The truth table of fsQCA has the knack for providing a family of logically possible combination of causal relations and the accompanying outcomes (Dusa, 2019).

This study, therefore, leverages fsQCA as a case-oriented option to understand how complex solutions on the behavioural dispositions of MMS clientele can be actualised. The antecedents of MMS customers behavioural intentions are critically needed in such a competitive and technologically-bias environment. The MMS subscribers are defined by their distinct uniqueness relative to their complex behavioural dispositions. A complete knowledge on differing configurations of behavioural patterns for a set of outcomes is essential for optimal profit attainment. As demonstrated in the conceptual framework (Figure 2), the present study utilises the following constructs: brand equity (beq), security (sec), brand trust (brt), satisfaction (sat), and perceived quality (peq) as the antecedents of determining MMS subscribers' multiple solutions which result in continuous service utilization (csu).Contrary to symmetric methodologies, the set-theoretic condition (Figure 2), demonstrates the configurations of the study constructs which lead to the same outcome - i.e. MMS subscribers' intention towards continuous service usage.

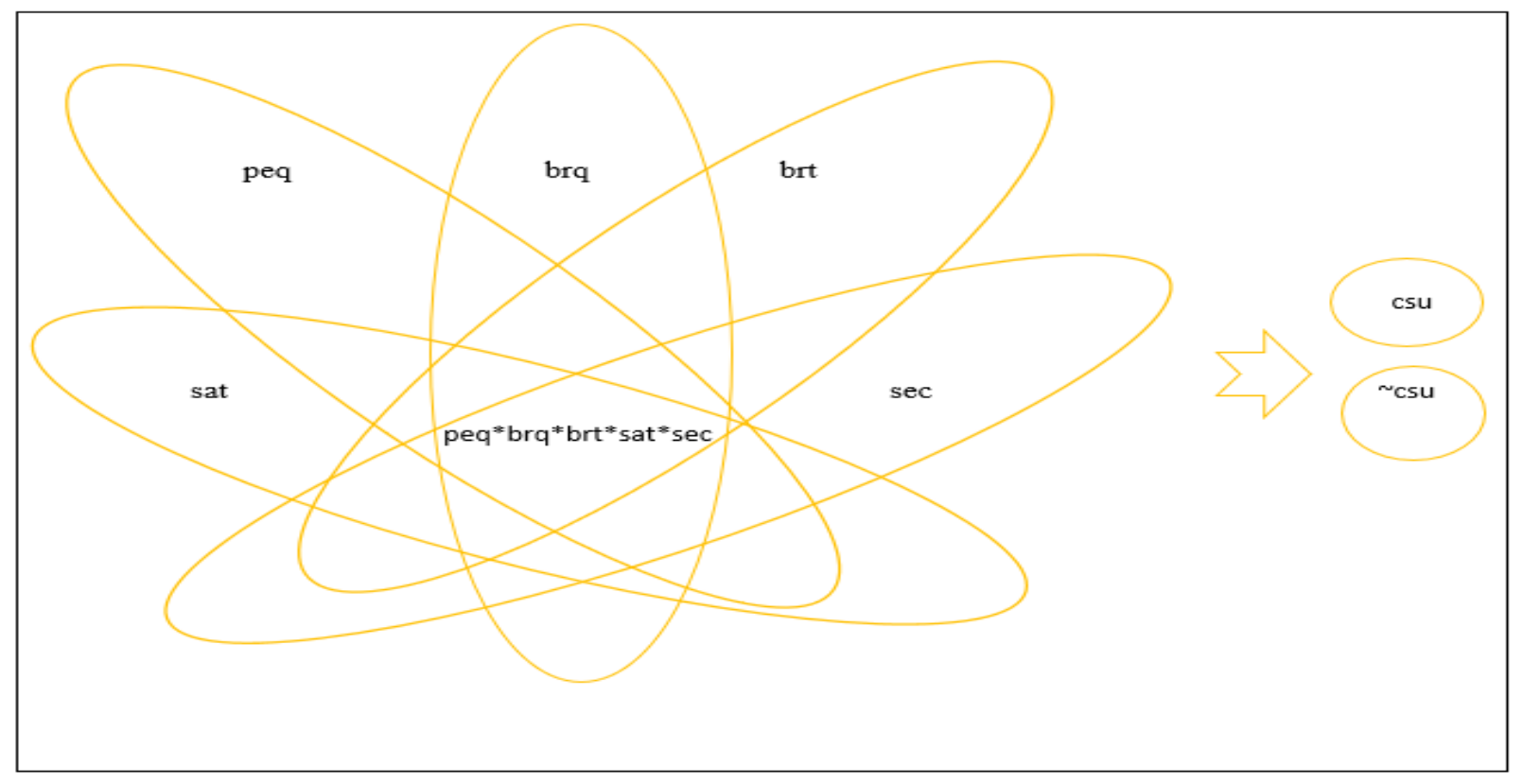

Figure 2. Configuration of complex systems based on the nexus between causal conditions for Equifinality.

Note: peq $=$ perceived quality; brq = brand equity; brt = brand trust; sat $=$ satisfaction; $\sec =$ security. 


\subsection{The goal of the study}

The present study is guided by two main goals. First, to use asymmetric methodology to explore the configurations of brand equity, satisfaction, security, brand trust, and perceived quality which lead to MMS subscribers' high behavioral intentions towards service providers. Second, to explore the constraining factors militating against the smooth operations of MMS.

\subsection{Methodology}

\subsection{Participants and settings}

The participants of the study consist of 417 (198 males and 219 females) MMS subscribers, with an age range of 20 and 40 years. In terms of educational background, 70, of them had received pre-secondary/vocational education; 117, had received secondary/diploma education; 149 of them had bachelor degree; lastly, 76 and 5 had their masters and terminal degrees respectively. Furthermore, the order of participant's preference for MMS provider is: 186 for MTN, 100 for Vodafone, 92 for Tigo and, 39 for Airtel.

\subsection{Measures}

To enhance the accuracy in measuring MMS subscribers' behavioral intentions, a five-point Likert scale survey instrument was developed. The range of the questionnaire was between strongly disagree (1) and strongly agree. The study constructs - security, brand equity, satisfaction, brand trust, perceived quality and continuous service utilization were operationalized from prior literature to inform the crafting of the study questionnaire. The study constructs were coded as sec for security; bre for brand equity; peq for perceived quality; sat for satisfaction; brt for brand trust and csu for continuous service utilization. In all, the participants of the study completed 25 operationalized scale items with the following breakdown:

\subsection{Security}

The study participants completed four operationalized items on security (Goa et al, 2014, Hsu et al 2015). The items on security were crafted to mirror the safety of wealth and privacy of personal data of MMS subscribers. Samples of the items on security are: "My MMS provider guarantees the protections of customers' wealth"; "My MMS provider assures the protections of customers' personal information"; and "My MMS provider has a structured policy that covers customers in the event of accidental loss". An average variance extraction (AVE) and Cronbach's alpha values of 0.72 , and 0.91 , respectively were reported from the scores on security.

\subsection{Perceived quality}

The authors measured three items from perceived quality (Parasuraman, et al, 1988; Xu, Peak, \& Prybutok, 2015). Perceived quality items are as follow: "My MMS provider offers prompt service"; "My MMS provider offers convenient service"; and "My MMS provider offers personalized and professional financial service". The AVE and the Cronbach's alpha statistics for perceived quality scores were respectively 0.64 , and 0.90 .

\subsection{Satisfaction}

We adapted five items from prior literature to measure satisfaction (Xu et al., 2015; Parasuraman,et al, 1988) to reflect the level of service usage fulfillment. Examples of the drafted items on satisfaction are: "I am very satisfied with how my MMS provider handles clients"; "I am highly satisfied with the overall office atmosphere of my MMS 
provider"; and "In general, I am very satisfied with the kind of services rendered by my MMS provider". The scores on satisfaction produced an AVE of 0.64, and a Cronbach's alpha value of 0.90 .

\subsection{Brand trust}

Following Aaker (1991) and Morgan \& Hunt (1994) five items for brand trust were crafted to demonstrate brandbased trust. Among these five items are: "I have an utmost level of trust for my MMS provider"; "I am highly certain that my MMS provider will not act contrary to its value propositions"; "I trust that my MMS provider is reliable and delivers on its promises" and "I trust that my MMS provider legally operates within the framework of Banking and Insurance laws of Ghana". Statistically, the scores for brand trust generated an AVE of 0.73, and a Cronbach's alpha value of 0.92 .

\subsection{Brand equity}

Four items were adapted from extant literature to reflect brand equity (Aaker, 1991; Hoeffler \& Keller, 2002). Samples of these items are: "My MMS provider has a unique corporate niche in terms of product offering"; "My MMS provider is well established and the most popular for reliable insurance provision" and; "My MMS provider is innovative and is known to operate a propitious business model". Brand equity scores yielded an AVE of 0.57, and 0.84 Cronbach's alpha.

\subsection{Intentions for continuous service utilization}

The authors measured four items on intentions for continuous service utilization (Parasuraman et al, 1988; Xu et al., 2015). These items include: "I shall continue to utilize the services of my MMS provider"; "I shall continually recommend the services of my MMS provider to others"; and "I shall stick to my MMS provider unconditionally". The scores on continuous service utilization recorded 0.54, as an AVE and a Cronbach's alpha value of 0.84.

\subsection{Constraining factors of MMS smooth operation}

We administered opened-ended questionnaires for participants to freely express the operational challenges in the MMS industry. Sample of answers from the participants are: "[...] mobile money merchants do not carry out their banking services in an enclosed and secure place"; "[...] some of us are working in constant fear of being attack by armed robbers"; "[...] the level of competition is unbearable"; "[...] we are challenged by cyber-induced crimes"; and " $[\ldots]$ the flow of our service is sometimes truncated as a result of unwarranted tampering of our cables".

\subsection{Procedure}

Due procedural etiquettes and protocols of the University of Electronic Science and Technology of China on research was conscientiously observed before the study was commissioned. Participants who were used in the study were first briefed on the purpose of the study and consent for their participation was sought thereafter. The survey instruments were administered via traditional and nontraditional - i.e. social media to enhance sample representativeness.

\subsection{Data Analysis}

In order to adhere to the recent reportage against the restriction of scientific enquiries outcomes on null hypotheses testing (NHST), the present study endeavored to use both traditional and non-traditional statistical techniques to significantly improve the efficiency, reliability and the validity of the results. To this end, SEM and fsQCA were 
utilized as our main techniques in the study. These techniques were carefully chosen based on their respective uniqueness in relation to the objectives of the study.

The authors religiously adhered to recommended diagnostic checks and other mediation practices in order not to violate any of the protocols of SEM namely, multivariate normality, sample size, positive definitiveness and multicollinearity (Kline, 2016). Furthermore, to improve model fit analysis subsequent to model identification, a number of modification indices measures were observed to obtain a minimum discrepancy and parsimonious fit. Analysis of moment structures (AMOS 22) graphics and IBM SPSS version 22 were used for SEM analysis. Tosmana 1.6 and fs/QCA 2.5, (Ragin \& Sean, 2009) software tools were used for counterfactual analysis prior to the determination of all logical combinations. In particular, statistics on raw coverage, unique coverage, overall solution consistency and coverage under fsQCA truth table were duly acknowledged. The foregoing was aimed at conducting somewhat precise outcome testing (SPOT) as a complement to NHST.

\subsection{Results and Discussions}

\subsection{Confirmatory measurement}

Confirmatory Factor Analysis (CFA) was conducted as an initial step to handle issues pertaining to constructs reliability and validity. The reliability of the constructs was benchmarked on the Cronbach's alpha statistics, while the Average Variance Extracted (AVE) was used as the barometer for convergent validity. Both reliability and validity statistics for the study constructs were found to be within the recommended values - Tables 1 and 2 (Kline, 2016).

Table 1. Standard deviation, mean and correlation matrix of study constructs

\begin{tabular}{lllllllll}
\hline Constructs & SD & Mean & SEC & PEQ & BRE & SAT & CSU & BRT \\
\hline SEC & 0.942 & 2.34 & - & & & & & \\
PEQ & 0.720 & 3.84 & 0.233 & - & & & \\
BRE & 0.701 & 3.97 & 0.212 & 0.641 & - & & & \\
SAT & 0.910 & 3.48 & 0.231 & 0.352 & 0.464 & - & & \\
CSU & 0.815 & 3.03 & 0.353 & 0.252 & 0.263 & 0.542 & - & \\
BRT & 0.732 & 3.96 & 0.251 & 0.513 & 0.531 & 0.491 & 0.342 & - \\
\hline
\end{tabular}


Table 2. Psychometric properties of observed variables

\begin{tabular}{|c|c|c|c|}
\hline $\begin{array}{l}\text { Observed } \\
\text { variables }\end{array}$ & Loadings & $\begin{array}{l}\text { AVE (Recommended } \\
\text { value: }>0.5)\end{array}$ & Cronbach's alpha (Recommended value: $\geq 0.7)$ \\
\hline BRT 1 & 0.84 & \multirow{5}{*}{0.73} & \multirow{5}{*}{0.92} \\
\hline BRT 2 & 0.89 & & \\
\hline BRT 3 & 0.88 & & \\
\hline BRT 4 & 0.81 & & \\
\hline BRT 5 & 0.72 & & \\
\hline SAT 1 & 0.73 & \multirow{5}{*}{0.64} & \multirow[t]{5}{*}{0.90} \\
\hline SAT 2 & 0.87 & & \\
\hline SAT 3 & 0.86 & & \\
\hline SAT 4 & 0.77 & & \\
\hline SAT 5 & 0.78 & & \\
\hline SEC 1 & 0.81 & \multirow{4}{*}{0.72} & \multirow[t]{4}{*}{0.91} \\
\hline SEC 2 & 0.84 & & \\
\hline SEC 3 & 0.89 & & \\
\hline SEC 4 & 0.85 & & \\
\hline BRE 1 & 0.52 & \multirow{4}{*}{0.57} & \multirow[t]{4}{*}{0.84} \\
\hline BRE 2 & 0.75 & & \\
\hline BRE 3 & 0.79 & & \\
\hline BRE 4 & 0.74 & & \\
\hline PEQ 1 & 0.89 & \multirow{3}{*}{0.54} & \multirow[t]{3}{*}{0.84} \\
\hline PEQ 2 & 0.89 & & \\
\hline PEQ 3 & 0.70 & & \\
\hline CSU 1 & 0.56 & \multirow{4}{*}{0.69} & \multirow[t]{4}{*}{0.87} \\
\hline CSU 2 & 0.80 & & \\
\hline CSU 3 & 0.76 & & \\
\hline CSU 4 & 0.80 & & \\
\hline
\end{tabular}

fsQCA output

Configurations of brand equity, satisfaction, security, brand trust, and perceived quality which lead to MMS subscribers' high behavioral intentions towards service providers

The results in Table 3, reveals that there are twelve (12) complex solutions which define MMS subscribers' behavioral outcomes.

These are:

$\sim$ SAT*BRT*BRE*PEQ*SEC;SAT*BRT*BRE*PEQ*SEC; SAT*BRT*BRE* PEQ*SEC; SAT*BRT* BRE* PEQ*SEC;SAT*BRT*BRE*PEQ* SEC;SAT*BRT*BRE* PEQ*SEC; SAT*BRT*BRE* PEQ* SEC;SAT*B 
RT $\sim$ BRE* $^{*} \sim \mathrm{PEQ}^{* S E C}$;SAT* ${ }^{*}$ BRT*BRE* ${ }^{*}$ PEQ $^{*} \sim$ SEC;SAT* BRT* BRE*PEQ*SEC; SAT*BRT*BRE*PEQ $\sim$ SEC;and $\sim$ SAT $^{*} \sim$ BRT $^{*}$ BRE* $^{*} \sim$ PEQ*SEC.

In consistent with ChanShen (2013), Litler and Melanthieus (2006), solution 1, combines brand trust (BRT), brand equity (BRE), perceived equity (PEQ) and security (SEC), to explain MMS subscribers' high intentions towards service adoption and continuance patronage. Solution 1 has a consistency of 0.97 . It also shows a considerable amount of causal conditions with high intentions to partake in MMS (Its coverage $=0.55$ ). Solution 2, demonstrates that to achieve a high level of subscribers' intentions to partake in MMS, an effective combination of satisfaction (SAT), brand trust (BRT), brand equity (BRE), perceived equity (PEQ) and security (SEC) is required. Solution 2, which collaborates with the findings of MaAfee (2013) has a consistency of 0.89 , and a coverage of 0.37 . Solution 3 , on the other hand shows that MMS subscribers' high intentions towards service providers can be achieved when brand trust (BRT), brand equity (BRE) and security (SEC) are combined. Solution 3 produced a consistency of 0.73 , and a coverage of 0.31 . According to solution 4, a combination of brand trust (BRT) and security (SEC) will also yield a scenario of subscribers' high intentions to participate in MMS. The pathway of solution 4 yielded a consistency of 0.91 , and a coverage of 0.32 .

Furthermore, solution 5 demonstrates that, a combination of satisfaction (SAT), brand trust (BRT), brand equity (BRE) and perceived quality (PEQ) will result in subscribers' high intentions to participate in MMS. This is consistent with the prior studies by Gwahula (2016) and Melanthieus (2006). The consistency and coverage values of solution 5 are respectively given as 0.83 , and 0.23 . Similarly, solution 6 , suggests that the unification of brand trust (BRT), brand equity (BRE), satisfaction (SAT) and security (SEC) will lead to MMS subscribers' high intentions towards service providers. The trajectory of solution 6 has a consistency of 0.92 , and a coverage of 0.17 . Additionally, solution 7, demonstrate that the fusion of brand trust (BRT) and brand equity (BRE) will have a unique trajectory which will lead to MMS subscribers' high intentions to patronize their service. The trajectory of solution 7 , also has a consistency of 0.95 , and a coverage of 0.23 . According to solution 8 , an attainment of MMS subscribers' high intentions towards service providers is feasible when brand trust (BRT), satisfaction (SAT) and security are combined. In line with this, solution 8 produced a consistency and a coverage of 0.78 , and 0.32 respectively.

Solution 9, shows that MMS subscribers' high intentions towards service providers can be achieved whenever brand equity (BRE) and satisfaction (SAT) are combined. Solution 9 produced a consistency of 0.95 , and a coverage of 0.53. Solution 10, projects that a combination of satisfaction (SAT), perceived quality (PEQ) and security (SEC) will lead to MMS subscribers' high intentions towards service providers. The pathway of solution 10 has a consistency of 0.92 , and a coverage of 0.17 . With reference to solution 11, MMS subscribers will exhibit high intentions to participate in MMS when brand trust (BRT), brand equity (BRE) and perceived quality (PEQ) are combined. Solution 11 has a consistency of 0.89 , and a coverage of 0.20 . Lastly, solution 12 , which has a consistency of 0.82 , and a coverage of 0.31 , demonstrates that a configuration of brand equity (BRE) and security (SEC) will cause MMS subscribers to develop a behavioral disposition of high intentions towards service providers (Table 3).

In the context of fsQCA, consistency simply refers to the degree of approximated relations. Coverage assesses the empirical relevance pertaining to identical consistent subgroups. The overall solution coverage measures the degree 
to which high intention to participate in MMS can be established on the basis of the set of combinations (Dusa, 2019; Ragin, et al, 2003; Thiem et al, 2016). Overall solution coverage is analogous to R-square in traditional statistics (Woodside et al., 2017). Table 3, shows a recommended overall solution coverage of 0.94 (Dusa, 2010; Ragin \& Sean, 2009). This demonstrates that a considerable amount of the variation (94\%) in MMS subscribers' behaviour has been explained by our twelve complex solutions. Other metrics which fsQCA estimates are the raw coverage and the unique coverage. These metrics are intended to guesstimate the empirical relevance of each configural solution. In detail, raw coverage involves the extent to which an outcome is explained by other competing configural solutions. Unique coverage, on the other hand, explains the extent to which an outcome is explained exclusively by other competing configural solutions (Dusa, 2010; Ragin \& Sean, 2009). Furthermore, the twelve complex solutions suggest that a considerable number of MMS subscribers (17\% -55\%) have high intention to participate in MMS (Table 3).

Table 3. Configurations of High Intentions of Continuous Service Utilization

\begin{tabular}{|c|c|c|c|c|c|c|c|c|c|c|c|c|}
\hline $\begin{array}{l}\text { Solutions/ } \\
\text { Constructs }\end{array}$ & 1 & 2 & 3 & 4 & 5 & 6 & 7 & 8 & 9 & 10 & 11 & 12 \\
\hline SAT & (x) & $\bullet$ & (x) & (x) & $\bullet$ & $\bullet$ & (x) & $\bullet$ & $\bullet$ & $\bullet$ & (x) & $(\mathrm{x})$ \\
\hline BRT & $\bullet$ & $\bullet$ & $\bullet$ & $\bullet$ & $\bullet$ & $\bullet$ & $\bullet$ & $\bullet$ & $(\mathrm{x})$ & (x) & $\bullet$ & $(\mathrm{x})$ \\
\hline BRE & $\bullet$ & $\bullet$ & $\bullet$ & (x) & $\bullet$ & $\bullet$ & $\bullet$ & $(\mathrm{x})$ & $\bullet$ & $(\mathrm{x})$ & $\bullet$ & $\bullet$ \\
\hline PEQ & $\bullet$ & $\bullet$ & (x) & $(\mathrm{x})$ & $\bullet$ & (x) & (x) & (x) & (x) & $\bullet$ & $\bullet$ & $(\mathrm{x})$ \\
\hline SEC & $\bullet$ & $\bullet$ & $\bullet$ & $\bullet$ & (x) & $\bullet$ & (x) & $\bullet$ & (x) & $\bullet$ & (x) & $\bullet$ \\
\hline Consistency & 0.97 & 0.89 & 0.73 & 0.91 & 0.83 & 0.92 & 0.95 & 0.78 & 0.95 & 0.88 & 0.89 & 0.92 \\
\hline Raw coverage & 0.55 & 0.37 & 0.31 & 0.32 & 0.23 & 0.17 & 0.25 & 0.32 & 0.53 & 0.34 & 0.20 & 0.31 \\
\hline Unique coverage & 0.16 & 0.07 & 0.02 & 0.00 & 0.10 & 0.17 & 0.13 & 0.02 & 0.04 & 0.01 & 0.16 & 0.13 \\
\hline $\begin{array}{l}\text { Overall solution } \\
\text { consistency }\end{array}$ & 0.80 & & & & & & & & & & & \\
\hline $\begin{array}{l}\text { Overall solution } \\
\text { coverage }\end{array}$ & 0.94 & & & & & & & & & & & \\
\hline
\end{tabular}

Note. $(\bullet)$ demonstrates the presence of a condition whereas (x) demonstrates the absence of a condition. Source: fsQCA/Tosmana output from field data.

3.2 Constraining factors militating against the smooth operations of MMS

Technological services are mostly impaired by some identifiable challenges which in turn affect continuance of service usage negatively. From the foregoing, the study identified some challenges which mitigate against the operation of MMS across the value chain. These challenges have been categorized into subscriber-specific and service-provider-specific. 
Under subscriber-specific challenges, the study identified that the main challenges of MMS subscribers are cyber fraud, risky servicescape, uneven distribution of MMS merchants, poor network and difficulties in keeping PIN code (Figure 3).

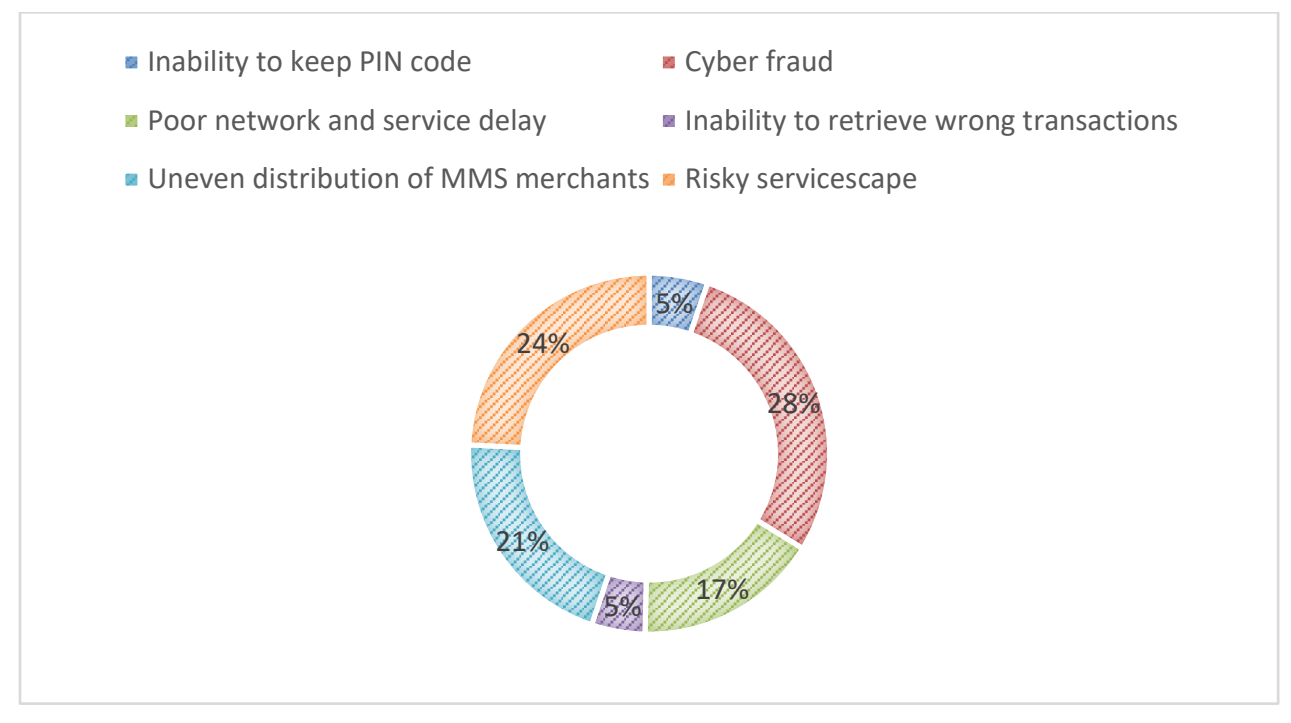

Figure 3. Constraining Factors of MMS Against Subscribers

With regards to MMS merchants' challenges, the findings of the study essentially revealed that the main challenges of merchants are centered on cyber-related crimes, challenges to recover wrong transactions, poor network, robbery attack, low financial literacy among MMS subscribers and inadequate electronic funds in consistent with literature (Apostolos, et al, 2012; McAfee, 2013; Thales e-Security 2019; Yu, Kywe, \& Li, 2018) (Figure 4). Similarly, Figure 5, depicts the operational challenges of MNOs. These challenges are: high cost of operation induced by excessive competition, cyber fraud, cable theft and related problems such as low financial literacy among a section of the subscribers.

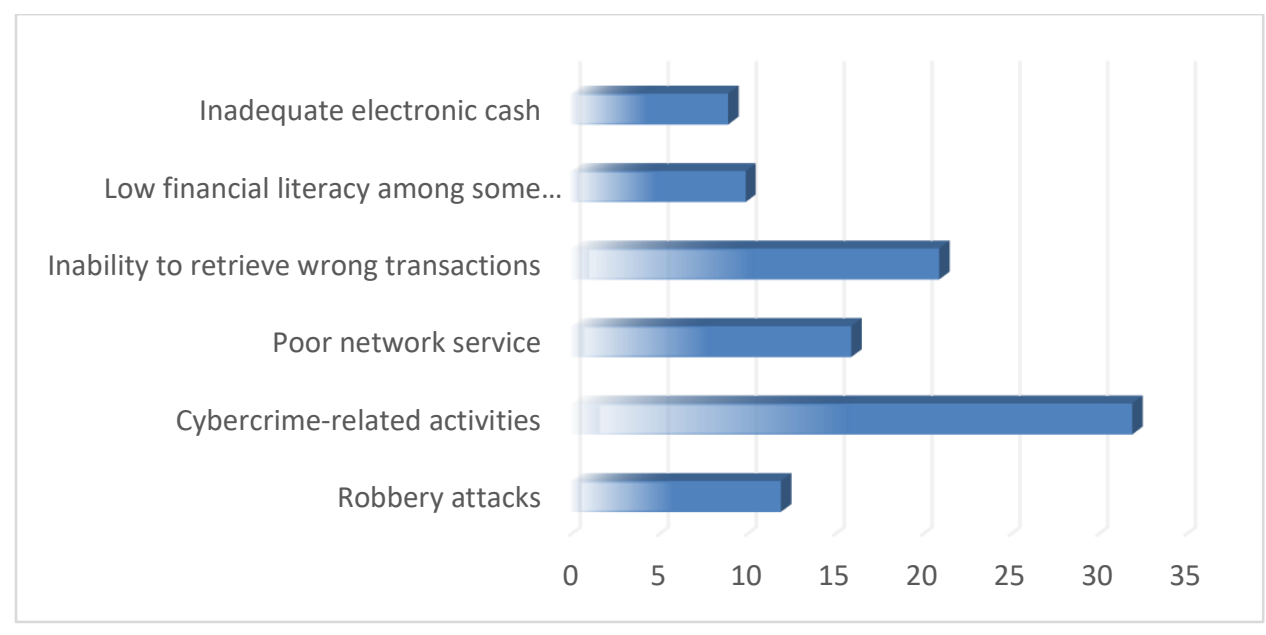

Figure 4. Constraining Factors of MMS Against Merchants 


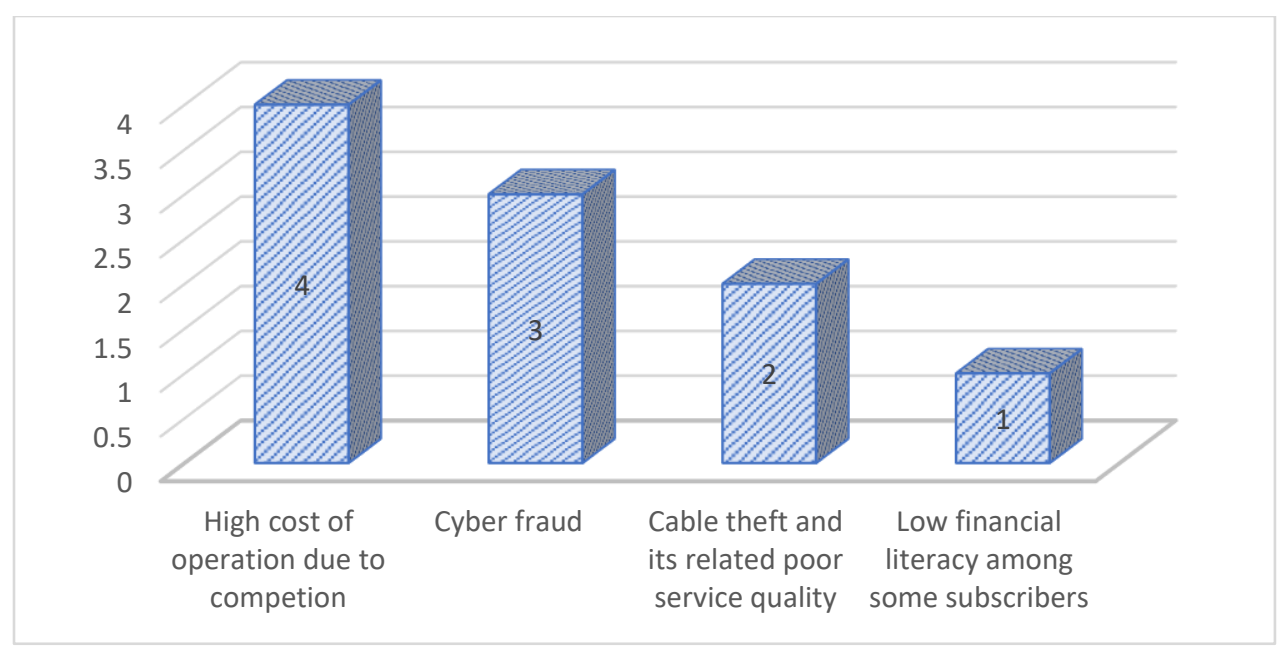

Figure 5. Constraining Factors of MMS Against MNOs

\subsection{Theoretical and practical implications}

The study makes a compelling contribution to literature. In a stark contradiction to the popular practice in prior literature, the present study stands as the first attempt to apply a nontraditional approach to investigate the behavioral dispositions of MMS subscribers. On the back of this, the study, contributes immensely to the stream of literature on complexity theory and fsQCA.

The study has also made some practical contributions as well. First, the study cogently spells out the behavioral diversity of MMS subscribers through a set of complex solutions. The foregoing provides a comprehensive view on MMS subscribers' behavioral disposition. This will enable managers to provide tailor-made services to meet the expectations of the entire spectrum of the MMS clientele. Second, the study has outlined challenges of the MMS stakeholders across the value chain. To improve service quality and clientele loyalty, managers should endeavor to bring under control the prevailing phenomena of cyber fraud, poor network quality, uneven distribution of MMS vendors and the incessant complaint of electronic funds (Gwahula, 2016). Third, it is proposed that managers should ascertain the security of prospective MMS vendors before licensing rights are given to them; while making sure that there is a continuous effort to improve the level of financial literacy among MMS subscribers via mass media.

\section{Conclusion}

The findings of the present study suggest that MMS subscribers' behavioral disposition is complex, and thus, it can only be efficiently explained via a configural of complex solutions; and not under symmetric methodology environment. In view of this, twelve complex solutions were deduced from a six-factor model to inform MMS industry players decision-makings. Furthermore, the authors identified some critical factors which war against the smooth operations of the MMS industry, and have accordingly, outlined practical proposals on how to rest them. These include the development of smart anti-cyber fraud measures, liaising with accredited banks to ensure constant supply of electronic funds, and provision of enough education on the usage of MMS. 


\section{Limitation and future research direction}

The study used brand trust, satisfaction, brand equity, security, and perceived quality as the main constructs for the counterfactual analyses of MMS subscribers' behavioral dispositions. There may be other defining constructs of MMS subscribers' behaviors which can be explored in future studies.

\section{References}

Aaker, D. A. (1991). Managing Brand Equity: Capitalizing on the Value of a Brand Name. The Free Press, 15.

Anderson, R. E. Swaminathan, S. (2011). Customer satisfaction and loyalty in e-markets: A PLS path modeling approach. The Journal of Marketing Theory and Practice, 19(2), 221-234.

Apostolos, N. G., Spyridon, B., \& Polychronopoulo, G. (2012). An extension of TAM model with IDT and security/privacy risk in the adoption of internet banking services in Greece. EuroMed Journal of Business, 7(1), 1450-2194.

Ardey, T. N. (2016). Who Regulates the Mobile Money Operations by Telco's? The Need for an Effectiv and Robust Legislative and Regulatory Framework in Ghana. Journal. Journal of Business and Financial Affairs, 5(3). https://doi.org/10.4172/2167-0234.1000208

Awadzi, E. A. (2018). Banking crisis-the role of the regulator. Koforidua.

Bank, F. R. (2017). Current use of mobile banking and payments. New York.

Bank, G. C. (2017a). Payment systems department. Impact of mobile money on the payment system in Ghana: an econometric analysis. Accra.

Bank, G. C. (2017b). Payment systems oversight annual report, bank of Ghana. Accra.

Boateng, H., Adam, D. R., Okoe, A. F., \& Anning-Dorson, T. (2016). Assessing the determinants of internet banking adoption intentions: a social cognitive theory perspective. Computers in Human Behavior, 65, 468-478. https://doi.org/10.1016/j.chb.2016.09.017

Boulding, W., Kalra, A., Staelin, R., \& Zeithaml, V. A. (1993). A dynamic process model of service quality: From expectations to behavioral intentions. Journal of Marketing Research, 30(1), 7-27.

ChauShen, C. (2013). Perceived risk, usage frequency of mobile banking services. Managing Service Quality, 23(5), 410 436.

Demirguc-Kunt, A., Klapper, L., Singer, D., Ansar, S., \& Hess, J. (2018). The global Findex database 2017: Measuring financial inclusion and the fintech revolution. Washington, D.C.

Donovan, K. (2012). Mobile money for financial inclusion, in Information and Communication for Development. Washington, D.C.

Dusa, A. (2010). A mathematical approach to the Boolean Minimization problem. Qual Quant, 14(1), 99-113.

Dusa, A. (2019). QCA with R: A Comprehensive Resource. Gewerbestrasse: Springer International Publishing AG, part of Springer Nature.

Gahigi, \& Moses, K. (2017). Mobile Money is only starting to transform some of Africa's Markets. Retrieved July 10, 2018, from https://qz.com/africa/1039896/m-pesa-mtn-orange-others-lead-africas-mobile-moneyrevolution/

Ghana, B. of. (2017). The Impact of Mobile Payment Systems.

Ghana, B. of. (2018). Mobile money accounts outstriped population size. Retrieved from paemuka.com/mobile-money- 
accounts-outstrip-ghanas-population/

Ghana, M. (2018). Mobile Money Performance in Ghana. Retrieved October 20, 1BC, from $\mathrm{mtn} . \mathrm{com} . \mathrm{gh} / \mathrm{personal} / \mathrm{mobile}-\mathrm{money} /$ about-mobile-money

Ghana Banking Survey: The Future of Banking in Ghana ...What's next? (2014). Retrieved from www.pwc.com/gh/en/assets/pdf/gh-banking-survey-2014.pdf. Retrieved on January, 2018.

GSMA. (2017). Mobile Money is driving global market. Retrieved July 10, 1BC, from /www.businesswire.com/news/home/20170711005846/en/GSMA-Sub-Saharan-Africa-Driving-GlobalMarket-Mobile

Gwahula, R. (2016). Risks and Barriers Associated with Mobile Money Transactions in Tanzania. Business Management and Strategy, 7(2), 121-139.

Hawass, H. H. (2013). Brand trust: implications from consumer doubts in the egyptian mobile phone market. Journal of Islamic Marketing, 4(1), 80-100.

Hoeffler, S., \& Keller, K. L. (2002). Building Brand Equity Through Corporate Societal Marketing. Journal of Public Policy \& Marketing, 21(1), 78-89.

Hoeffler, S., \& Keller, K. L. (2003). The Marketing Advantages of Strong Brands. Journal of Brand Management, 10(6), $421-445$.

Kapferer, J. N. (1998). Strategic Brand Management: Creating and Sustaining Brand Equity Long Term (second). London: Kogan Page.

Kline, R. B. (2016). Principles and Practice of Structural Equation Modeling (4th ed.). New York: The Guildford Press.

Kohli, C., \& Thakor, M. (1997). Branding Consumer Goods: Insights form Theory and Practice. Journal of Consumer Marketing, 206-219.

Kotler, P., \& Pfoertsch, W. (2007). Being Known or Being One of Many: The Need for Brand Management for Business-to-Business Companies. Journal of Business and Industrial Marketing, 22(7), 357-362.

Lee, H. J., \& Jee, Y. (2016). The impacts of brand asset of domestic screen golf playing systems upon brand trust and brand loyalty. International Journal of Sports Marketing and Sponsorship, 17(4), 320-333.

Lee, R., \& Neale, L. (2012). Interactions and consequences of inertia and switching costs. Journal of Services Marketing, 26(5), 365-374.

Littler, D., \& Melanthiou, D. (2006). Consumer perceptions of risk and uncertainty and the implications for behaviour towards innovative retail services: the case of internet banking. Journal of Retailing Consumer Service, 13(6), 431443.

Max, M., \& McKay, C. (2018). Building inclusive payment ecosystems in Tanzania and Ghana. Washington, D.C.

McAfee. (2013). Mobile Security: McAfee Consumer Trends Report (Trends in risky apps, mobile misbehavior, and spyware). Retrieved from www.mcafee.com/us/resources/reports/rpmobile-security-consumer-trends.pdf

Morgan, R. M., \& Hunt, S. D. (1994). The commitment-Trust Theory of Relationship Marketing. Journal of Marketing, 54(3), 20-38.

Oliva, T. A., Oliver, R. L., \& MacMillan, I. C. (1992). A catastrophe model for developing service satisfaction strategies. Journal of Marketing, 56(3), 83-95.

Owusu, K. K., Atiemo, K. A. O., \& Appiah, C. (2019). Acceptance and use of mobile banking: an application of 
UTAUT2. Journal of Enterprise Information Management, 32(1), 118-151.

Parasuraman, A.; Zeithaml, V. A.; Berry, L. L. (1988). SERVQUAL: a multiple-item scale for measuring consumer perceptions of service quality. Journal of Retailin, 64(1), 12-37.

Pavlou, P. A., Tan, Y. H., \& Gefen, D. (2003). The transitional Role of Institutional Trust in Online Interorganizational Relationships. In Proceedings of the 36th Annual Hawaii International Conference on System Sciences (pp. 10-20). IEEE.

Polites, G. L., \& Karahanna, E. (2012). Shackled to the status quo: The inhibiting effects of incumbent system habit, switching costs, and inertia on new system acceptance. MIS Quarterly, 36(1), 21-42.

Ragin, C. C., \& Fiss, P. (2008). Net effects versus configuration: an empirical demonstration. In Ragin (2008a)., 190212.

Ragin, C. C., \& Sean, D. (2009). fxQCA/: Fuziyy-set/ Qualitative Comparative Analysis. Irvine: Department of Sociology, University of California.

Ragin, C. C., Shulman, D., Weinberg, A., \& Gran, B. (2003). Complexity, Generality and Qualitative comparative analysis. Field Methods, 15, 323-340.

Shem, A. O., Teresa, M., \& Maureen, W. (2017). Mobile financial Services and Financial Inclusion :Is It A Boon for Savings Mobilization? Review of Development Economics, 7, 29-35.

Thales e-Security, Smart Cards for Payment System, Thales e-Security Ltd,. (n.d.). Buckinghamshire, pp. 1-2. Retrieved from www.thales-esecurity.com

Thiem, A., Spöhel, R., \& Dusa, A. (2016). Enhancing sensitivity diagnostics for qualitative comparative analysis: a combinatorial approach. Political Analysis, 24, 104-120. https://doi.org/doi.org/10.1093/pan/mpv028

Wei-Tsong, W., Wei-Ming, O., \& Wen-Yin, C. (2019). The impact of inertia and user satisfaction on the continuance intentions to use mobile communication applications: A mobile service quality perspective. International Journal of Information Management, 44(2019), 178-193.

Woodside, A. G. (2015). Embrace perform model: complexity theory, contrarian case analysis, and multiple realities. Journal of Business Research, 67(12), 2495-2503.

Woodside, A. G., Garbor, N., \& Megehee, C. M. (2017). Applying complexity theory: A Primer for identifying and modeling firm anomalies. Journal of Innovation and knowledge.

Woodside, A. G., Prentice, C., \& Larsen, A. (2015). Revisiting problem gamblers' harsh gaze on casino services: applying complexity theory to identify exceptional customers. Psychology\& Marketing, 32(1), 65-77.

Wu, P. L., Yeh, S. S., Huan, T. C., \& Woodside, A. G. (2014). Applying complexity theory to deepen service dominant logic: Configural analysis of customer experience-and-outcome assessments of professional services for personal transformations. Journal of Business Research, 67(8), 1647-1670.

Xu, C., Peak, D., \& Prybutok, V. (2015). A customer Value, Satisfaction, and loyalty Perspective of Mobile Application Recommendations. Decision Support Systems, 79, 171-183.

Yu, X., Kywe, S. M., \& Li, Y. (2018). Security issues of in-store mobile payment. In: Handbook of Blockchain, Digital Finance, and Inclusion (2nd ed.). Academic Press.

Zeithaml, V. A., Berry, L. L., \& Parasuraman, A. (1985). Problems and Strategies in Service Marketing. Journal of Marketing, 49(2), 39-46.

Zeithaml, V. A., Berry, L. L., \& Parasuraman, A. (1988). SERVQUAL: A Mulitple-Item Scale for Measuring Consumers Perceptions of Service Quality. Journal of Retailing, 64(1), 12-37.

Zhao, A. L., Hanmer-Lloyd, S., Ward, P., \& Goode, M. M. H. (2008). Perceived risk and Chinese consumers' Internet banking services adoption. International Journal of Bank Marketing, 26(7), 505-525. 